crease access to health care for most Canadians. "The CMA has now marginalized itself. It has shown it is out of touch with its members and certainly with the majority of Canadians. I hope it will now ... figure out what the organized leadership of the profession should be doing for the health of Canadians rather than acting in the best interest of the profession."

Medical students also expressed concerns about the contradictions. "I hope they will come up with a consistent statement that puts patients first," said Andre Bernard, president of the Canadian Federation of Medical Students (CFMS), representing 6500 students in the I3 Anglophone schools. "I'm not convinced we're hearing all sides of the argument."

The Student Medical Reform Group, a grassroots movement, presented CMA with a petition decrying the move to allow more private medicare, signed by II34 students representing all of Canada's medical schools (CMAJ 2006; I75:I8). The petition points out that 2-tier health care in other countries promotes queuejumping and lengthens wait-times in the public system. Many have argued the public-private debate is moot given that there aren't enough physicians in Canada to run parallel systems and that the wait-times issues can't be resolved without redressing the current shortage of physicians, as London, Ont. anesthesiologist Dr. Ron Wexler repeatedly told General Council.

Other approved motions included: a call for more transparent tendering as governments enter more public-private partnerships; development of a code of conduct for physicians who provide health services that are delivered publicly and privately; adoption of the waittime code recommended by the CMA; and establishment of evidence-based wait-time benchmarks for all major diagnostic, emergency, therapeutic and surgical services by Dec. 3I, 2007.

"What we need is the medical equivalent of a building code," said Comox, BC delegate Dr. Jon Slater. "Other countries have done this; it's time for Canada to get with the program." Barbara Sibbald, CMAJ

\section{New Day dawns}

Published at www.cmaj.ca on August 22, 2006

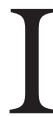
n a hotly contested campaign, orthopedic surgeon Dr. Brian Day, the founder of Vancouver's private, for-profit Cambie Surgery Centre, was elected Aug. 22 at the CMA General Council as CMA president-elect for 2006/07. He will succeed Dr. Colin McMillan as president for 2007/08.

In February, Day defeated 5 candidates in 5 ballots to win the BCMA nod to stand as CMA's president-elect at General Council. Dr. Jack Burak was a close second and agreed not to run against Day. The CMA presidency rotates among the provinces and territories.

But a number of influential physicians persuaded Burak, a Vancouver family physician, former BCMA president, to change his mind and muster a candidacy, which he announced July II.

This is only the third time in CMA's history that the presidency has been contested.

As per CMA policy, only the winner, not the vote count, was announced, although Day received a standing ovation.

In his election speech, Day, aged 59, said he sought the position because "Canadians are not being well served by our health care system."

Day has come under intense media scrutiny for his ties to the private clinic and his presumed support of privatization. He pleaded with the press to "listen to what I say, not what you say I say."

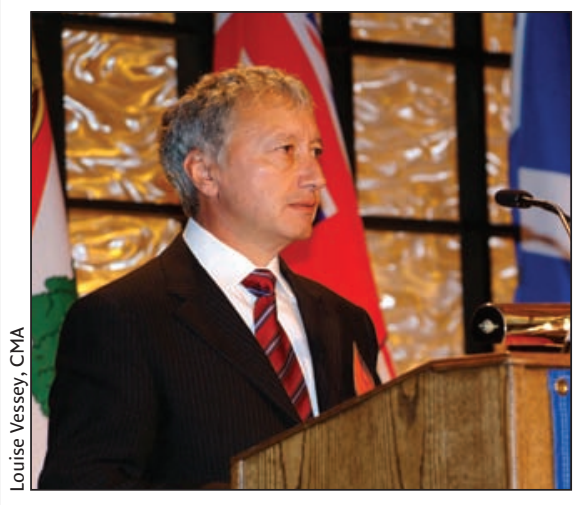

Newly-elected CMA president and orthopedic surgeon Dr. Brian Day vows to ensure that Canadians continue to receive timely access to health care regardless of ability to pay.
Day insisted he's "never supported the privatization of medicare." But "like most physicians and most Canadians I believe there is a place for the private sector and for public-private partnerships."

Day vowed that "as president-elect of the CMA I commit to a policy that all Canadians receive timely access to medically necessary services regardless of ability to pay. My support for universal health care is unequivocal."

"No CMA policies will change in any radical way with my election."

Day also pledged to "update" the Canada Health Act to include accountability, efficiency, equality and specific measures to eliminate wait lists and the suffering of children. "CMA needs to ... oppose anything that's not in the best interest of patients."

Burak, meanwhile, emphasized his I9-year involvement with the BCMA and CMA, and ran on a platform of "supporting a strong publicly funded health care system." He told CMAJ he was "naturally disappointed" at the election results, but added that he supports the decision of the delegate-voters and will "continue to be a member of the board of directors of CMA and assist Dr. Day in whatever way I can."

"Dr. Day is a breath of fresh air and maybe physicians felt it was time we had someone who could perhaps push us a little harder for options for change," Burak said, adding that he recognizes the system must change. "But I prefer to make changes within the publicly funded system."

The rooo-member Canadian Doctors for Medicare (CDM), formed in May to stop what it sees as CMA's drift to twotier medicine, opposed Day's nomination and view of health care reform.

"Given that he's been elected we're going to hold him to his word that [his position at the CMA] will not be a platform for his views alone, but the views of all Canadian doctors," said the Chair of CDM's board, Dr. Danielle Martin.

Outgoing CMA president Dr. Ruth Collins-Nakai stressed "CMA policy has not changed as a result of this election. We remain committed to Canadians' timely access to publicly funded health care." — Barbara Sibbald, CMAJ

DOI:Io.I503/cmaj.o6rog6 